\title{
YOUR CHILD IS MY CHILD: COMMUNITY EDUCATION IN SEXUAL ABUSE FOR A HIGH RISK AREA
}

\section{Herman Grobler, Claudi van den Heever}

\section{INTRODUCTION}

Sexual abuse of children is a reality that has been present for centuries (Bandi, 2003:1) and research has indicated that the rate of sexual abuse of children is extremely high (Karson, 2001:4). Most parents find it difficult to discuss the topic of sexual abuse with their adolescents, and even more with their pre-school children. This is understandable, as it might even be difficult for parents to discuss general sexual matters with their children. The complexity of the issue is highlighted by Myers and Milner (2007:2), who refer to sex and sexuality as complicated because of the "different discourses, labels and identities" that influence the way people make sense of sexual matters. They also refer to the lack of discussion of sexual matters, or the ways in which these matters are discussed that can lead to confusion. According to Lively and Lively (1991:74), even parents in affluent families may not always explain the sexual act when their children see them having intercourse. This may confuse the children. Children who are exposed to sexual activities on a daily basis can become vulnerable in terms of sexual abuse, because the context of the sexual behaviour is not explained. The parents also do not necessarily teach the children to protect their own bodies and that sexual activities should be reserved for when they are mature.

According to the literature (Potgieter, 1996:38; Prilleltensky, Nelson \& Peirson, 2001:64-101), there are various causes of sexual abuse in the system (consisting of society, the community, the family and the individual). In high-risk areas economic factors, social isolation, individual factors and family factors contribute to this problem. Factors that play a role on all levels of the system include housing, overpopulation, privacy, relationships between parents, poverty, unemployment, and broken and unstable families. For the purpose of this study these factors comprise what has been termed the "high risk area". According to official estimates, reports of child sexual abuse in North America have increased significantly since 1980 (Miller-Perrin \& Perrin, 1999:110). With an increased incidence of sexual abuse reports in South Africa, and sexual abuse thus being a major problem in our society (Spies, 2007:44), sexual education in terms of personal safety skills and community awareness and participation becomes critical (Gordon \& Schroeder, 1995:17).

In order to clarify the context in which the study upon which this article is based was undertaken, a short overview and background of sexual abuse is given, after which the research methodology and research results are discussed. The aim of this article is to provide knowledge regarding the safeguarding of pre-schoolers against sexual abuse within a high-risk area.

\section{BACKGROUND AND CONTEXTUAL FACTORS}

According to the Constitution of South Africa, 1996 (Act No. 108 of 1996, section 28), every child has the right to be protected against abuse, neglect and degradation. Furthermore, the best interest of the child is the most important consideration in every case involving children; a child is a person younger than 18 years.

Although child abuse, and especially sexual abuse, has received much attention over the past three decades, an annual increase of $29 \%$ in the sexual abuse of children in South Africa was still being reported in 1996 (Potgieter, 1996:2). Statistics of the South African Police Service 
for 2005/2006 show that in the Gauteng province alone 1171 cases of neglect and abuse of children were reported. According to the 2003 statistics available from Child Welfare South Africa (2003), 4526 sexually abused children were dealt with each month in the whole of South Africa. Of these children, $89 \%$ were female and $27 \%$ of the total were between zero and five years old. In most cases relatives were responsible for the abuse. Despite public awareness and children's rights, these numbers remain significantly high.

As far as child development is concerned, more attention is devoted to the sexual education of adolescents. It can therefore be asked whether sexual education is addressed early enough. Parents offer various arguments why sexual education is not seen as part of their task (Gordon \& Schroeder, 1995:12) and, with an already full and busy curriculum, teachers have limited time to address the issue. The only formal sexual education initiated by the Department of Education occurs in Grade 7 (Abrahamse, 2007), in other words, at the beginning of puberty. According to the literature (Gordon \& Schroeder, 1995; Heinze, 2000; Wurtele, 1990; Wurtele, Kast, Miller-Perrin \& Kondrick, 1998), preventative sexual education programmes can also be successful for pre-schoolers.

A lack of knowledge among community members, parents and pre-schoolers may have several negative implications. Exposure to sexual behaviour that is not explained to children may leave them confused. This exposure may also have an effect on their school performance, as it is known that difficult circumstances at home could negatively influence school performance (Potgieter, 1996:77; Sciarra, 2004:392). Inappropriate sexualised behaviour can occur. Gordon and Schroeder (1995:10) found that children between two and seven years from a low socio-economic background have less knowledge of body parts and their functions, pregnancy and the prevention of abuse. Children are also attentive and constant observers of their parents and are also inclined to do what they see, not what they are told. Gordon and Schroeder (1995:11) emphasise that, in the area of sexual abuse, more experience does not necessarily indicate a better comprehension and more knowledge. Children experiment with sexual behaviour out of curiosity and when they are not informed in a way that is suitable for their developmental phase and environment, inappropriate behaviour can occur that could become problematic. Potgieter (1996:73-85) is of the opinion that sexually abused children, children who observe adult sexual activities or who are exposed to pornographic material will show behaviour that includes characteristics of sexualised play, premature sexual awareness and inappropriate sexual behaviour.

Parents find it difficult to discuss sexuality with their children, but at the same time children are exposed to sexual practices and media images with sexual insinuations and explicit depictions of sexual deeds which encourage them to be sexually active. According to Palmary (2003), fifty thousand rapes are reported every year in South Africa. In about half of these cases children under the age of 18 years are involved and about forty percent of these cases are committed by children younger than 18 years. As already mentioned, preparation for sexual exposure is not necessarily a priority for parents of toddlers or the local community, but according to the above-mentioned statistics it is indeed necessary, especially if we take into consideration that over-populated dwellings are a reality for many of South Africa's residents.

It is clear from the above that parents as well as the community have a responsibility in respect of the incidence of sexual abuse of children. It is important that both parents and the community set aside their passivity and begin to assume an active role to determine which factors within the community contribute towards sexual abuse and protect children against it. When the community denies its role, parents are left alone to fight the battle against sexual abuse of children and this can possibly lessen the opportunities for success. A community that 
is aware can make an active contribution towards the protection of children, and especially preschoolers, against sexual abuse.

\section{RESEARCH METHODOLOGY}

The aim of this research was to investigate the knowledge base and needs of parents and other role-players in a high-risk community in connection with community education in terms of the protection of pre-schoolers against sexual abuse, so that possible guidelines can be laid down that can empower these role-players in terms of the sexual education of these children.

A quantitative research approach was followed. Applied research, together with its exploratory and descriptive nature, was identified as the most suitable kind of research because its purpose is to solve problems in practice (Fouché \& De Vos, 2005:105-106; Grinnell \& Unrau, 2005:1417). The randomised cross-sectional survey (Graziano \& Raulin, 2007:148; Grinnell \& Unrau, 2005:204) seemed to be the best option for a research design as questionnaires served as the main data-gathering method.

In the random selection process, purposive sampling was the most suitable method for this study (Babbie \& Mouton, 2001:166; Strydom, 2005:202). All the role-players or parties concerned with the pre-schoolers of the Danville community were involved in the random sample, although participation was voluntary. Sixty-four respondents were needed to be representative of the population. Role-players or interested parties who were involved included 38 parents, one psychologist, nine teachers, two members of the community, four social workers, two school principals, five speech therapists and two occupational therapists, as well as two theologians (pastors and ministers).

Because of the sensitive nature of the study, it was decided to use questionnaires to gather information on the respondents' feelings, opinions, perceptions and motivations, as well as their personal, educational and financial background (Maree, 2003:46). It was of the utmost importance that the questionnaire be worded in such a manner that the questions could be easily understood and explained to suit the educational level of the parents. The researcher compiled two questionnaires, one for the parents and another for the professional role-players, seeing that the questions for the different groups would sometimes differ to ensure optimal data gathering. The questionnaires were divided into three categories in the light of the literature study which was done beforehand, namely biographical information, sexual abuse and prevention of sexual abuse.

Validity and reliability (Grinnell \& Unrau, 2005:135-145) were ensured to make certain that the information gathered would be relevant and useful. To ensure content validity, indicators were identified from the literature and questions were formulated accordingly. The specific concepts that were measured for the purpose of this study included sexual abuse of toddlers and preventing it, possibly through community education. The questionnaires were divided into three specific and relevant categories, where the questions in each category reflected the main concept in order to ensure face validity. It was important that the questions reflected the main concepts, namely sexual abuse of toddlers and prevention through community education and the need for prevention. For criterion validity, the results were compared with the available literature and statistics, where possible, to determine the degree of concurrence. The following steps were taken to ensure reliability:

- Constructs were clearly conceptualised. A clear, theoretical definition was formulated for each construct and general constructs such as "toddler", were clearly defined in order to 
prevent confusion. Questions were kept as simple as possible and contained only one construct;

- The researcher tried to elicit detailed information by making use of both open and closeended questions. In the case of close-ended questions, as many representative categories as possible were set up. These questions also reflected an "other" option, where respondents could enter a personal answer if the categorisation of answers was insufficient;

- Each aspect of the variable was measured by more than one question, for example "What does sexual abuse of toddlers mean to you?" and "Do you think sexual abuse of toddlers is..." followed by four categories to choose from;

- The questionnaires were tested by administering a trial run and thus ensuring that there was no confusion and that the meaning of the questions and instructions was clear.

Data were manually analysed to identify constructs (Delport, 2005:188) from the questionnaires. These constructs also often overlapped with the indicators for the questionnaire; the frequency of their occurrence was determined and then explained and discussed in the form of visual presentations. Conclusions and recommendations concerning the study were made on the basis of this analysis.

\section{EMPIRICAL FINDINGS}

\section{Biographical information}

Biographical information of respondents serves as background to understand the field of the respondents better. On the other hand, the field serves as a frame of reference for the empirical results that were obtained from the study.

Respondents who participated voluntarily in the study were mostly women. Of the parents who took part, $89 \%$ were female and the professional role-players also consisted of $89 \%$ females and only $11 \%$ males. The parents were mainly in the 30 to 39 years age group, followed by 19 to 29 years, and the professional role-players were between 18 to 29 years, followed by 30 to 39 years. In terms of racial groups, $95 \%$ percent of the parents were white and $5 \%$ black and coloured. Of the professional role-players, 93\% were white and 7\% black and coloured. Of the children of the parents, $55 \%$ were boys and $45 \%$ were girls. These pre-schoolers were mainly the first or second children.

Fifty percent $(50 \%)$ of the parents have a Grade 10 to Grade 12 certificate, followed by $32 \%$ who have a Grade 8 or 9 certificate, and $11 \%$ who only progressed to Grades 4 to 7 . Five percent $(5 \%)$ of the parents received tertiary education. According to the qualifications of the professional role-players, $55 \%$ received tertiary education and $15 \%$ are in possession of a Grade 10 or Grade 12 certificate, or completed non-academic training courses.

Forty-eight percent of the professional role-players are involved with the pre-schoolers in Danville on a daily basis. The role-players who are involved daily are mainly teachers, one or two community members and the social workers. Other professional role-players such as occupational therapists, speech therapists, psychologists, pastors and ministers are involved with the Danville pre-schoolers from one to four times per week: $26 \%$ are involved once a week, $19 \%$ two to three times a week, and only $4 \%$ are involved 4 times a week (Table 1 ). The terms of involvement of professional role-players (Table 2) mainly vary between one year $(33 \%)$, two years $(22 \%)$ and three to five years $(30 \%)$. The conclusion can be drawn that the majority of professional role-players worked in Danville for less than five years. 
TABLE 1

WEEKLY INVOLVEMENT OF PROFESSIONAL ROLE-PLAYERS

\begin{tabular}{|l|c|c|c|c|c|}
\hline TIMES PER WEEK & Daily & 4x per week & 2-3x per week & 1x per week & Sometimes \\
\hline PERCENTAGE $(\%)$ & 48 & 4 & 19 & 26 & 3 \\
\hline
\end{tabular}

TABLE 2

PERIOD OF INVOLVEMENT OF PROFESSIONAL ROLE-PLAYERS

\begin{tabular}{|l|c|c|c|c|c|}
\hline NUMBER OF YEARS & $\mathbf{0 - 1}$ year & 2 years & $\mathbf{3 - 5}$ years & $\mathbf{6 - 1 0}$ years & $\mathbf{1 0 +}$ years \\
\hline PERCENTAGE $(\%)$ & 33 & 22 & 30 & 7,5 & 7,5 \\
\hline
\end{tabular}

\section{Family circumstances}

It appears that most parents who participated in the study are relatively aware of the core element of sexual abuse of pre-schoolers, namely one or other form of sexual behaviour, for example, touching the child's genitals, rape, sexual harassment by a male person or exposure. However, $43 \%$ of the parents could not really give a written description of what sexual abuse of a child entails. Professional role-players express various opinions on parents' awareness of the concept of sexual abuse, but the collective opinion is that $74 \%$ of the parents are aware of it to a greater or lesser degree. However, $89 \%$ of the parents and $89 \%$ of the professional role-players confirmed that sexual abuse comprises both physical sexual touching and exposure to sexual behaviour or material which is also linked to the various types of sexual abuse, when the question was presented in multiple-choice format. Contradictions in the above-mentioned findings are the result of the different presentation of the questions used to gather the data.

Among the parents, $82 \%$ are of the opinion that the perpetrator can be any person (strangers, family members, neighbours or other members of the community). Professional role-players think that in most cases the perpetrator is someone who is trusted by the victim, such as a family member (29\%) or family friend (29\%). Parents had to specify whether there had been a previous incident of sexual abuse of a family member, and according to $53 \%$ of these cases the perpetrator was a relative of the victim, either a biological relative or step-relative. In only $21 \%$ of these cases was the perpetrator someone from outside the family.

The respondents had various opinions concerning the regularity of sexual abuse of children. According to $49 \%$ of the respondents, sexual abuse of pre-schoolers takes place regularly. A total of $15 \%$ of the respondents were aware of a pre-schooler who was being sexually abused.

In answer to the question "What will you do if you know of a child that is being sexually abused?" 78\% of the parents replied that they would report it. According to the professional role-players, such a case would be reported by $66 \%$ of the parents. The opinions of the professional role-players are based on information which was gathered through interviews, the completion of official forms, and conversations with the people from Danville while delivering their different professional services. When, however, the question was formulated differently, namely, "How important do you think it is to report sexual abuse to the social worker or the police?" $100 \%$ of the parents and $96 \%$ of the professional role-players confirmed the necessity of reporting the sexual abuse of a toddler, whereas $4 \%$ believed it is not necessary. 
On the level of society and community the causal factors of sexual abuse of pre-schoolers overlap and these factors are discussed below.

In terms of poverty and impoverishment, $50 \%$ of the parents indicated that the total monthly income of the family was less than R2000 00 per month. Some of the professional role-players $(52 \%)$ were of the opinion (based on their professional experience and relations with the people of Danville) that the amount was between R2000 00 and R5000 00 per month and 35\% mentioned that to the best of their knowledge it was below R2000 00 per month. A total of $43 \%$ of the respondents mentioned that the total income per month of the residents in Danville was less than R2000 00 per month. According to the respondents, the main expenses of a family are as follows: Food and housing (22\%), cigarettes and tobacco (14\%), personal items such as toothpaste and shampoo (12\%) and childcare $(9 \%)$.

Unemployed parents comprised $61 \%$ of all parents who took part in the study. The professional role-players put the figure at $54 \%$.

According to the empirical findings, $33 \%$ of the families live in a house, $22 \%$ in a room, $18 \%$ share a house and $8 \%$ live in a Wendy house. Respondents further indicated that some of the houses consisted of one room (families that live in a room and houses with only one room). Families who live in a house (whether alone or sharing) indicated that the houses have an average of three rooms and that one or two families live there. The mere fact that $22 \%$ of the families live in a room and $8 \%$ in Wendy houses - a total of $30 \%$ - is already an indication of inadequate housing.

Exposure to various forms of violence was mentioned by the respondents as a causal factor in terms of sexual abuse. Pre-schoolers are exposed to various forms of violence. According to $28 \%$ of the respondents, they are exposed to violence in the media, $23 \%$ mention violence on the streets, $23 \%$ violence in the home and $18 \%$ mention crime (for instance, general crime and substance abuse). According to the professional role-players, $20 \%$ of the families spend money on cigarettes and tobacco, $18 \%$ on alcohol and $5 \%$ on drugs.

From the empirical findings the deduction can be made that the residents of Danville community get on reasonably well with each other and that social isolation is not really regarded as an issue in terms of sexual abuse, seeing that $47 \%$ of the parents felt that they get on very well with their neighbours, $47 \%$ get on quite well, $2 \%$ not at all and $2 \%$ "other". Professional role-players are of the opinion that $72 \%$ of the neighbours get on reasonably well and that $20 \%$ do not get on with each other at all.

Recurring family patterns can be regarded as a risk factor for sexual abuse of pre-schoolers. Fifty-two percent (52\%) of the parents mention that their own childhood was characterised by phenomena such as poverty, abuse, unhappiness and alcoholism. Professional role-players mention that a total of $77 \%$ of the parents were themselves exposed to poverty, violence, alcohol and drugs, abuse, neglect, unhappiness, conflict and social problems. Eleven percent $(11 \%)$ of the professional role-players refer to the cyclic course, where circumstances and certain factors are repeated for generations. It can further be seen that $47 \%$ of the parents are always aware of where and with whom their pre-schoolers are and $37 \%$ are mostly aware of the whereabouts of their pre-schoolers, something that can minimise the risk of sexual abuse of the pre-schooler. It seems that, according to more than half of the parents and professional roleplayers, recurring family patterns could be regarded as a risk factor for sexual abuse of preschoolers in Danville, although almost half of the parents try to be aware of their children's whereabouts. 


\section{Sexual development of the pre-schooler}

A total of $88 \%$ of the respondents indicated that pre-schoolers can indeed experience sexual stimulation, although they do not attach the same sexual connotation to it as adults. Sixty percent $(60 \%)$ of the respondents mention that a certain measure of sexual behaviour in preschoolers is not normal. Eighty percent $(80 \%)$ mention that it is acceptable for pre-schoolers to ask questions of a sexual nature such as "Where do babies come from?" or "Why doesn't John look like me?" and 55\% of the respondents mention that pre-schoolers do play sexual games that are acceptable, for example, "Show me yours and I'll show you mine".

Forty-nine percent (49\%) of the parents regard any form of sexual behaviour or sexual language that the pre-schooler uses in public as problematic behaviour. Professional roleplayers mainly specify concern about suggestive acts (44\%) and mention further factors such as masturbation (10\%), an excessive emphasis on sex (13\%), exposure (8\%) and sexual language $(10 \%)$.

A total of $37 \%$ of the parents are of the opinion that there is enough privacy at home for the sexual development of the pre-schooler not to be influenced by the parents' sexual behaviour, $31 \%$ think that there is a reasonable amount of privacy and $29 \%$ think that there is no privacy.

The empirical findings revealed that mostly white women participated voluntarily in the study. Parents mainly have a secondary education, with $50 \%$ who completed Grade 10 to 12 . The professional role-players are most qualified with a tertiary education. It seemed as if parents were aware of what sexual abuse is, but found it difficult to express the term in their own words. When considering previous sexual abuse within the family, it emerges that a relative or someone known to the child is usually the perpetrator; the professional role-players also found the perpetrator to be a relative or someone known to the child. All respondents agreed on the importance of reporting sexual abuse. Risk factors seem to include poverty, unemployment, inadequate housing (perceptions regarding available privacy differ), exposure to violence and recurring family patterns. Although the majority of respondents acknowledged that preschoolers can experience sexual stimulation without recognising it as such, almost half of the parents considered any sexual behaviour as problematic, with professionals mostly being concerned about suggestive acts.

\section{Community education and prevention of sexual abuse}

According to $95 \%$ of the respondents it is necessary to educate pre-schoolers in connection with the prevention of sexual abuse. Eighty-four percent $(84 \%)$ of the parents teach their preschoolers about personal safety and $76 \%$ teach their pre-schoolers about "stranger danger". Professional role-players also mention various structures that are already in place in Danville that contribute to the prevention of sexual abuse. These structures include, among others, the South African Police Service (25\%), social services (23\%), and schools and nursery schools $(15 \%)$. Only $22 \%$ of the professional role-players are, or have been, involved in a programme or intervention to protect pre-schoolers against sexual abuse.

According to the empirical findings, 94\% of the respondents think that parents are responsible for educating pre-schoolers for the prevention of sexual abuse and 74\% mention the school. Only $40 \%$ mention the government's responsibility and $52 \%$ state that this is a community responsibility (Table 3). According to $28 \%$, the community is to blame for sexual abuse of preschoolers and $15 \%$ are of the opinion that the government is to blame when a pre-schooler is sexually abused. 
TABLE 3

RESPONSIBLE PARTIES TO EDUCATE PRE-SCHOOLERS WITH REGARD TO THE PREVENTION OF SEXUAL ABUSE

\begin{tabular}{|c|c|c|c|c|c|c|}
\hline & \multicolumn{2}{|c|}{$\begin{array}{l}\text { PARENTS } \\
(\mathbf{n}=38)\end{array}$} & \multicolumn{2}{|c|}{$\begin{array}{c}\text { PROFESSIONAL } \\
\text { ROLE-PLAYERS }(n=27)\end{array}$} & \multicolumn{2}{|c|}{$\begin{array}{c}\text { TOTAL } \\
(\mathrm{n}=65)\end{array}$} \\
\hline & $\mathrm{n}$ & $\%$ & $\mathrm{n}$ & $\%$ & $\mathrm{n}$ & $\%$ \\
\hline PARENTS & 36 & $95 \%$ & 25 & $93 \%$ & 61 & $94 \%$ \\
\hline FAMILY & 16 & $42 \%$ & 14 & $52 \%$ & 30 & $46 \%$ \\
\hline COMMUNITY & 17 & $45 \%$ & 17 & $63 \%$ & 34 & $52 \%$ \\
\hline THERAPISTS & 0 & $0 \%$ & 23 & $85 \%$ & 23 & $35 \%$ \\
\hline FRIENDS & 13 & $34 \%$ & 3 & $11 \%$ & 16 & $25 \%$ \\
\hline MEDIA & 17 & $45 \%$ & 9 & $33 \%$ & 26 & $40 \%$ \\
\hline SCHOOL & 27 & $71 \%$ & 21 & $78 \%$ & 48 & $74 \%$ \\
\hline GOVERNMENT & 16 & $42 \%$ & 10 & $37 \%$ & 26 & $40 \%$ \\
\hline NOBODY & 0 & $0 \%$ & 0 & $0 \%$ & 0 & $0 \%$ \\
\hline OTHER & 2 & $5 \%$ & 0 & $0 \%$ & 2 & $3 \%$ \\
\hline
\end{tabular}

Views on the role of the community are seen as confused, according to the empirical findings. Most of the respondents (89\%) regard sexual abuse as a community issue and a further $75 \%$ mention that the assistance and support of a whole community is necessary to guide preschoolers successfully to adulthood. Yet only $46 \%$ of the respondents regarded a supportive community as contributing to the prevention of sexual abuse.

Views on protective factors against the sexual abuse of pre-schoolers were also obtained from the empirical findings. On a community level, strong social values are regarded as protective measures by $71 \%$ of the respondents, and social awareness of sexual abuse was seen as a protective measure by $65 \%$ of the respondents. On the local community level, only $46 \%$ of the respondents mention social support, $62 \%$ mention sufficient resources, $75 \%$ a supportive school environment and $55 \%$ a positive community climate. Yet $91 \%$ of the respondents mention the cooperation of various role-players in the community (e.g., parents, therapists, school personnel, the community, government). Good communication (60\%) and strong family ties $(68 \%)$ were identified as important protective factors within the family, but it seems as if only $34 \%$ of the average parents get on fairly well with each other. It seems as if parents have a strong awareness of the comings and goings of pre-schoolers $(51 \%)$. The empirical findings indicate that the opinions of parents and of professional role-players differ about pre-schoolers' exposure to inappropriate situations in the family. It does indeed seem that there is a $50 \%$ chance that pre-schoolers are exposed to such situations.

Community members are to some extent aware of what the term "sexual abuse of preschoolers" means (including "genitals are touched, rape, sexual harassment by a male person and exposure"). They are further aware that sexual abuse of pre-schoolers takes place on a regular or daily basis (respectively $49 \%$ and $43 \%$ ). According to $15 \%$ of the respondents, there are currently pre-schoolers in the community of Danville who are sexually abused. The factors which make pre-schoolers easy targets for sexual abuse are, among others, neglect by parents (35\%), pre-schoolers' innocence (18\%), their susceptibility to bribes (17\%) and unsatisfactory situations in the home $(12 \%)$. 
The core of the research was to determine the need for community education in order to provide knowledge regarding the safeguarding of pre-schoolers against sexual abuse in a highrisk area. The community of Danville indicates a great need $(97 \%)$ for community education regarding the protection of pre-schoolers against sexual abuse. Information needed for community education includes: a definition of sexual abuse (69\%), causes of sexual abuse (82\%), the prevention of sexual abuse $(78 \%)$, how to educate pre-schoolers themselves concerning sexual abuse $(82 \%)$ and the sexual development of the pre-schooler $(71 \%)$.

\section{CONCLUSION}

During the past five years, according to the empirical findings, there was an increase in involvement of various professional role-players (nursery school personnel, principals, social workers, occupational and speech therapists, psychologists and theologians) within the community of Danville. It seems as if pre-schoolers' lack of awareness about sexual abuse can be related to limited education and instruction provided by parents and professional roleplayers. It is also evident that parents and professional role-players are aware of the concept sexual abuse of a pre-schooler, but do not necessarily know exactly what it comprises. The community's lack of sufficient knowledge is shown by this. This can also be a possible explanation for the discrepancy between limited available statistics of sexual abuse reports to the SAPS and the Support Council and the many references for play therapy.

Any person can be regarded as a possible transgressor, but sexual abuse of a pre-schooler is mostly committed by a relative. It also appears that sexual abuse does not occur sporadically, which confirms that South Africa cannot yet be called child-friendly with regard to the law. Reporting the sexual abuse of pre-schoolers is regarded as being of the utmost importance.

In connection with the causes of sexual abuse, the following can be seen as causal factors on every level of the system.

On the level of society and the community, poverty is a determining factor. It appears that the community members of Danville live below the breadline in that $43 \%$ of pre-schoolers whose parents took part in the study have to survive on a total monthly income of under R2000 00. A total of 56\% of the pre-schoolers' parents in Danville are unemployed and this contributes to the poverty. A further reality in Danville is inadequate housing in that about $30 \%$ of the families live in a room or a Wendy house. There is a difference of opinion between the parents and the professional role-players regarding the measure of privacy as a result of different perceptions and frames of reference. The housing situation contributes to the fact that preschoolers are indeed exposed to a certain extent to various types of violence and this increases their risk of sexual abuse. It was, however, clear that the people of Danville get along reasonably well with each other and, as a result of this, social isolation is not a risk factor.

It appears that most of the parents are married and get on reasonably well with each other, but in some homes marital discord and violence in front of children can be seen as a risk factor. The cyclical course of sexual abuse indicates that pre-schoolers are indeed endangered because of the childhood years of their parents. Insufficient forms of discipline can be seen as a risk factor, but over against this is the fact that parents know most of the time where and with whom their pre-schoolers are. This serves as a protective factor. The conclusion can be drawn that the current circumstances within the family are not optimal for the protection of the pre-schoolers.

With regard to the sexual development and behaviour of pre-schoolers, it is apparent that the parents are confused as to what can be regarded as acceptable sexual development, behaviour, 
questions and playing, although the professional role-players are reasonably aware of what can be regarded as cause for concern. This is a further indication that community education is necessary. There is indeed a measure of consciousness of the prevention of sexual abuse in that parents teach their pre-schoolers about personal safely and "stranger danger".

According to the professional role-players, there are structures in place which also contribute to the prevention of the sexual abuse of pre-schoolers. These include, among others, the SAPS, social services and various therapists. The parents and schools have been identified as the parties mainly responsible for sexual education, followed by the government and the community to a lesser degree. The inconsistency is that it appears that the government and the community are mainly blamed for the high incidence of sexual abuse.

There is confusion regarding the role that the community can play concerning prevention of sexual abuse of pre-schoolers in that parents refer to community involvement as a society issue and demand the assistance of the community in raising pre-schoolers successfully, but indicate that a supportive community and community cooperation are not important.

Strong values and consciousness of society are regarded as important protective factors against sexual abuse. Furthermore, a supportive school environment and available resources for the community of Danville are important protective measures on the level of the community.

Consciousness forms the basis of prevention and protection of pre-schoolers against sexual abuse. Role-players are very conscious of the sexual abuse of pre-schoolers and this consciousness must be built upon to protect them against sexual abuse as far as possible. It is very clear that there is a great need for community education with regard to the safety of preschoolers. The community of Danville requires specific information on the definition of sexual abuse, its reasons and prevention, how to educate pre-schoolers in connection with sexual abuse and the sexual development of the pre-schooler.

\section{RECOMMENDATIONS}

Several recommendations can be made on the basis of the study. A community education programme must be developed with reference to this study, specifically with a view to the Danville community's need for sexual education concerning the safety of pre-schoolers. Professional role-players who are working in the Danville community must follow a multidisciplinary approach and cooperate to make a valuable contribution towards the protection of pre-schoolers against sexual abuse. A successful prevention strategy entails a partnership between all role-players and social levels, and includes cooperation between community members themselves and with other professional role-players.

Relevant parties such as social services, the Departments of Education and Social Development, the government and the South African Police Service have to be informed of the findings of this study. In this way, firstly, the pertinent role-players can be made aware of the prevailing circumstances which contribute to the sexual abuse of pre-schoolers in Danville and, secondly, this could possibly serve as an incentive to address the various aspects of this social issue according to each party's level of discourse and authority. Underlying issues that have to be addressed in order to contribute successfully to the prevention of sexual abuse of preschoolers are, for instance, housing, child and family care, unemployment, regular policing for the combating of violence and the drug trade, and the implementation of early, age-suitable prevention programmes for nursery schools. 


\section{REFERENCES}

ABRAHAMSE, A.E. 2007. School Principle, Generaal Beyers Primary School. Interview. 30 January 2007. Pretoria.

BABBIE, E. \& MOUTON, J. 2001. The practice of social research (SA ed). Oxford: Oxford University Press.

BANDI, G.T. 2003. The relationship between the quality of parenting skills and the vulnerability of children to sexual abuse. [Online] Available: http://www.epetd.up.ac.za/thesis/available/etd-10222004-073338. [Accessed: 03/04/2007.

CHILD WELFARE SOUTH AFRICA. 2003. Strategic Child Welfare statistical data confirms magnitude of statutory intervention. [Online] Available: http://www.Child welfaresa.org.za/oldweb [Accessed: 23/04/2009.

DELPORT, C.S.L. 2005. Quantitative data-collection methods. In: DE VOS, A.S., STRYDOM, H., FOUCHÉ, C.B. \& DELPORT, C.S.L. 2005. Research at grass roots - for the social sciences and human service professions $\left(3^{\text {rd }}\right.$ ed $)$. Pretoria: Van Schaik Publishers: 159-191.

FOUCHÉ, C.B. \& DE VOS, A.S. 2005. Problem formulation. In: DE VOS, A.S., STRYDOM, H., FOUCHÉ, C.B. \& DELPORT, C.S.L. 2005. Research at grass roots - for the social sciences and human service professions $\left(3^{\text {rd }}\right.$ ed). Pretoria: Van Schaik Publishers: 100-110.

GRAZIANO, A.M. \& RAULIN, M.L. 2007. Research methods: a process of inquiry (6 ${ }^{\text {th }}$ ed). Boston: Pearson Education, Inc.

GRINNELL, R.M. \& UNRAU, Y.A. 2005. Social work research and evaluation: quantitative and qualitative approaches $\left(7^{\text {th }}\right.$ ed $)$. New York: Oxford University Press.

GORDON, B.N. \& SCHROEDER, C.S. 1995. Sexuality: a developmental approach to problems. New York: Plenum.

HEINZE, E. 2000. Of innocence and autonomy: children, sex and human rights. Hampshire: Darmouth.

KARSON, M. 2001. Patterns of child abuse. New York: The Haworth Maltreatment and Trauma Press.

LIVELY, V. \& LIVELY, E. 1991. Sexual development of young children. New York: Delmar.

MAREE, J.G. 2003. Introduction to quantitative research. Pretoria: University of Pretoria: Faculty of Education.

MILLER-PERRIN, C.L. \& PERRIN, R.D. 1999. Child maltreatment: an introduction. London: SAGE Publications.

MYERS, S. \& MILNER, J. 2007. Sexual issues in social work. Bristol: The Policy Press.

PALMARY, I. 2003. Youth position paper presented at the Alliance for Crime Prevention Conference, Cape Town. [Online] Available: http://www.rapcan.org/za/German\%book.pdf [Accessed: 07/01/2007].

POTGIETER, R. 1996. 'n Model vir die assessering van die seksueel gemolesteerde kind onder die ouderdom van vyf jaar. Pretoria: University of Pretoria. (Unpublished DPhil Thesis) 
68

PRILLELTENSKY, I., NELSON, G. \& PEIRSON, L. 2001. Promoting family wellness and preventing child maltreatment: fundamentals for thinking and action. Canada: University of Toronto Press.

RSA MINISTRY OF LEGISLATION. 1996. Constitution of the RSA, 1996 (Act 108 of 1996). [S1]:[sn].

SCIARRA, D.T. 2004. School counselling: foundations and contemporary issues. Canada: Brooks/Cole-Thompson Learning.

SPIES, G.M. 2007. The effect of sexual abuse on a child. In: SPIES, G.M. (ed) Sexual abuse: dynamics, assessment \& healing. Pretoria: Van Schaik Publishers: 44-61.

STRYDOM, H. 2005. Sampling and sampling methods. In: DE VOS, A.S., STRYDOM, H., FOUCHÉ, C.B. \& DELPORT, C.S.L. 2005. Research at grass roots - for the social sciences and human service professions ( ${ }^{\text {rd }}$ ed). Pretoria: Van Schaik Publishers: 192-204.

WURTELE, S.K. 1990. Teaching personal safety skills to four-year-old children: a behavioral approach. Behavior Therapy, 22:69-83.

WURTELE, S.K., KAST, L.S., MILLER-PERRIN, C.L. \& KONDRICK, P.A. 1998. A comparison of programs for teaching personal safety skills to preschoolers. Journal of Consulting and Clinical Psychology, 57:505-511.

This article is based on a masters dissertation of limited scope.

Dr Herman Grobler, Department of Play Therapy, Huguenot College, Wellington; Ms Claudi van den Heever, Play Therapist/Psychometrist with welfare organisation in Pretoria, South Africa. 